\title{
Transport energy consumption in mountainous roads. A comparative case study for internal combustion engines and electric vehicles in Andorra
}

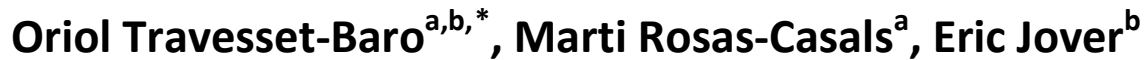

${ }^{a}$ Sustainability Measurement and Modeling Lab (SUMMLab), Universitat Politècnica de Catalunya (UPC), EET-Campus Terrassa, 08222 Barcelona, Spain

${ }^{b}$ Observatori de la Sostenibilitat d'Andorra (OBSA), Plaça de la Germandat 7, AD600 Sant Julià de Lòria, Andorra

\begin{abstract}
This paper analyses transport energy consumption of conventional and electric vehicles in mountainous roads. A standard round trip in Andorra has been modelled in order to characterise vehicle dynamics in hilly regions. Two conventional diesel vehicles and their electric-equivalent models have been simulated and their performances have been compared. Six scenarios have been simulated to study the effects of factors such as orography, traffic congestion and driving style. The European fuel consumption and emissions test and Artemis urban driving cycles, representative of European driving cycles, have also been included in the comparative analysis. The results show that road grade has a major impact on fuel economy, although it affects consumption in different levels depending on the technology analysed. Electric vehicles are less affected by this factor as opposed to conventional vehicles, increasing the potential energy savings in a hypothetical electrification of the car fleet. However, electric vehicle range in mountainous terrains is lower compared to that estimated by manufacturers, a fact that could adversely affect a massive adoption of electric cars in the short term.
\end{abstract}

\section{Keywords}

Energy consumption; road grade; driving cycle; electric vehicle; internal combustion engine; Andorra

\section{Introduction}

Transport accounts for $19 \%$ of global energy use and $23 \%$ of energy-related carbon dioxide $\left(\mathrm{CO}_{2}\right)$ emissions, and these percentages are set to rise in the future. Given current trends, transport energy use and $\mathrm{CO}_{2}$ emissions are projected to increase by nearly $50 \%$ by 2030 and more than $80 \%$ by 2050 (IEA, 2009). Within the European Union framework, $\mathrm{CO}_{2}$ emissions from road transport increased by nearly $23 \%$ between 1990 and 2010 . If it were not for the economic downturn, this percentage could have been even higher. In fact, transport is the only major sector in the EU where greenhouse gas emissions are still rising (European Commission, 2013). In recent years, alternative vehicle technologies look to address challenges associated with the current transport model, such as high dependence on oil, its contribution to global warming and the consequences of energy security issues, to name but a few. The future benefits of new vehicle technologies have been studied by many authors, both in terms of energy and $\mathrm{CO}_{2}$ savings (JRC et al., 2013; Lorf et al., 2013; Mari Svensson et al., 2007), but also from an economic, financial and European market perspective (Thiel et al., 2010). Nonetheless, most of these studies are based on standard driving cycles and are not necessarily representative of regional or local driving conditions.

Road grades and vehicle mass are known to have a significant impact on fuel consumption and emission levels (Boriboonsomsin and Barth, 2009; Frey et al., 2008; Park and Rakha, 2006). Few studies, however, have specifically investigated the influence of hilly roads on energy demand in electric vehicles. The New European Driving Cycle (NEDC), the legislative cycle in the EU countries for certifying vehicle fuel consumption and emission levels, tends to underestimate the consumption levels obtained under real-world conditions (Smith, 2010a; Tzirakis et al., 2006). This is due to the low acceleration rates considered and the fact that it doesn't take into account some parameters that affect fuel consumption (Burgess and Choi, 2003). Specificities of the route like orography are not considered in

\footnotetext{
* Corresponding author. Tel.: +34646653869 (O. Travesset-Baro)

E-mail address: travesset@gmail.com

Plaça de la Germandat 7, AD600, Sant Julià de Lòria, Andorra
} 
the NEDC, which could have a significant impact in some regions. Road grades and traffic operation of routes in mountainous roads imposes the need to develop a representative driving cycle for more accurate evaluation of fuel consumption in this type of roads.

The aim of this paper is to improve the understanding of vehicle dynamics in hilly regions and to implement methodologies to characterise fuel consumption. It also aims to analyse how specific aspects of electric vehicles, such as increments in mass linked with batteries and regenerative braking, affect the energy demand in mountainous roads. Andorra has been chosen as the subject of the case study. Its location in the middle of the Pyrenees means it has a hilly terrain with important road slopes. Urban roads are predominant because of the high demographic density. The transport sector is the main energy consumer of the country (39\% of primary energy consumed in 2011) and the leading source of greenhouse gas emissions (Andorra Government, 2012). Energy consumption related with transport, particularly road, has increased considerably over the last decades. Motor fuel imports increased from 111 million litres in 1993 to 130 million litres in 2012 (Department of Statistics, 2013).

In this paper, a real route in a mountainous region has been characterised to obtain data on energy consumption in car transportation. The study includes internal combustion engine vehicles (ICEVs) and electric vehicles (EVs) comparing their energy behaviour in mountainous roads, in general, and in Andorra, in particular. The paper is organised as follows. Methodology and assumptions are presented in Section 2. Section 3 provides the results and discussion. Finally, conclusions and some prospects for future work are presented in Section 4.

\section{Material and methods}

A spreadsheet-based model has been developed in order to analyse energy consumption in vehicles along the characterised route in Andorra. This section presents the energy consumption model, outlines the route, and provides the assumptions made during the modelling process.

\subsection{Energy consumption model}

A simplified model, based on the Vehicle Specific Power (VSP) equation (Jimenez-Palacios, 1999), has been used to describe the behaviour of vehicles along the route and estimate their energy consumption. Tractive effort required at the wheels $\left(\mathrm{F}_{\mathrm{te}}\right)$ for propelling the vehicle forward is calculated for every time step (one second for this model). Forces opposing the movement are considered (rolling resistance, aerodynamic drag) as well as hill climbing and inertial forces, which may be negative when the vehicle is going downhill or slowing down respectively. The total tractive effort equation is written as:

$$
\begin{aligned}
F_{t e} & =F_{r r}+F_{a d}+F_{h c}+F_{i}= \\
& =\mu_{r} \cdot m \cdot g \cdot \cos \alpha+0.5 \cdot \rho \cdot A \cdot C_{d} \cdot v^{2}+m \cdot g \cdot \sin \alpha+C_{i} \cdot m \cdot a[\mathrm{~N}]
\end{aligned}
$$

Where:

$F_{r r}$ is the rolling resistance force,

$F_{a d}$ is the aerodynamic drag,

$F_{h c}$ is the hill climbing force,

$F_{i}$ is the inertial force,

$\mu_{r}$ is the rolling resistance coefficient, $m$ mass of the vehicle, $g$ gravitational constant, $\alpha$ angle of road grade, $\rho$ air density, $A$ frontal area of the vehicle, $C_{d}$ drag resistance coefficient, $v$ vehicle speed, $C_{i}$ mass correction factor for rotational inertia acceleration, and $a$ vehicle acceleration.

Assuming a tank-to-wheels (TTW) analysis, the energy consumption is calculated at each section of road when any of the variables involved in the model change. This is mainly caused by road factors such as land profile or traffic control elements. The energy consumption of the route is given by:

$$
E_{T T W}=\frac{F_{t e} \cdot d_{e}}{\eta_{\mathrm{TTW}}} \quad[\mathrm{J}]
$$

where $d_{e}$ is the distance travelled for every constant tractive effort, and $\eta_{T T W}$ is the vehicle tank-to-wheels efficiency. 
The battery integrated in the EV can be recharged during deceleration with regenerative braking. The energy recovered during this process is given by:

$$
E_{r e c}=F_{t e} \cdot d_{r} \cdot \eta_{\mathrm{TTW}} \cdot \mathrm{E}_{\mathrm{RB}}[\mathrm{J}]
$$

where $d_{r}$ is the distance travelled in regeneration mode, and $E_{R B}$ is the wheels-to-battery regenerative efficiency. In this case, energy will be recovered by regenerative breaking when $\mathrm{F}_{\mathrm{te}}<0$.

Finally, energy consumption for the whole route for both EV and ICEV is calculated by:

$$
\begin{aligned}
& E_{T T W_{E V}}=\sum_{c y c l e} \frac{F t e_{E V} \cdot d e}{\eta_{T T W_{E V}}}-\sum_{c y c l e} E_{r e c} \quad[\mathrm{~J}] \\
& E_{T T W_{I C E V}}=\sum_{c y c l e} \frac{F t e_{I C E V} \cdot d e}{\eta_{T T W_{I C E V}}}
\end{aligned}
$$

\subsection{Route characterisation}

The route used in the model as a representative driving cycle in Andorra is the round trip between Andorra la Vella (the country's capital) and Canillo (a village northeast of the capital) along the main road (CG-2). The route has a distance of $24.6 \mathrm{~km}$, a mean road slope between Andorra la Vella and Canillo of $4.37 \%$, and a maximum grade of 12.5\%. This route starts and finishes at Andorra la Vella and goes through Escaldes-Engordany and Encamp (second and third villages in number of inhabitants, respectively). It is currently the most transited route in the country. Fig. 1 shows the geographical location of Andorra and the characterised route.

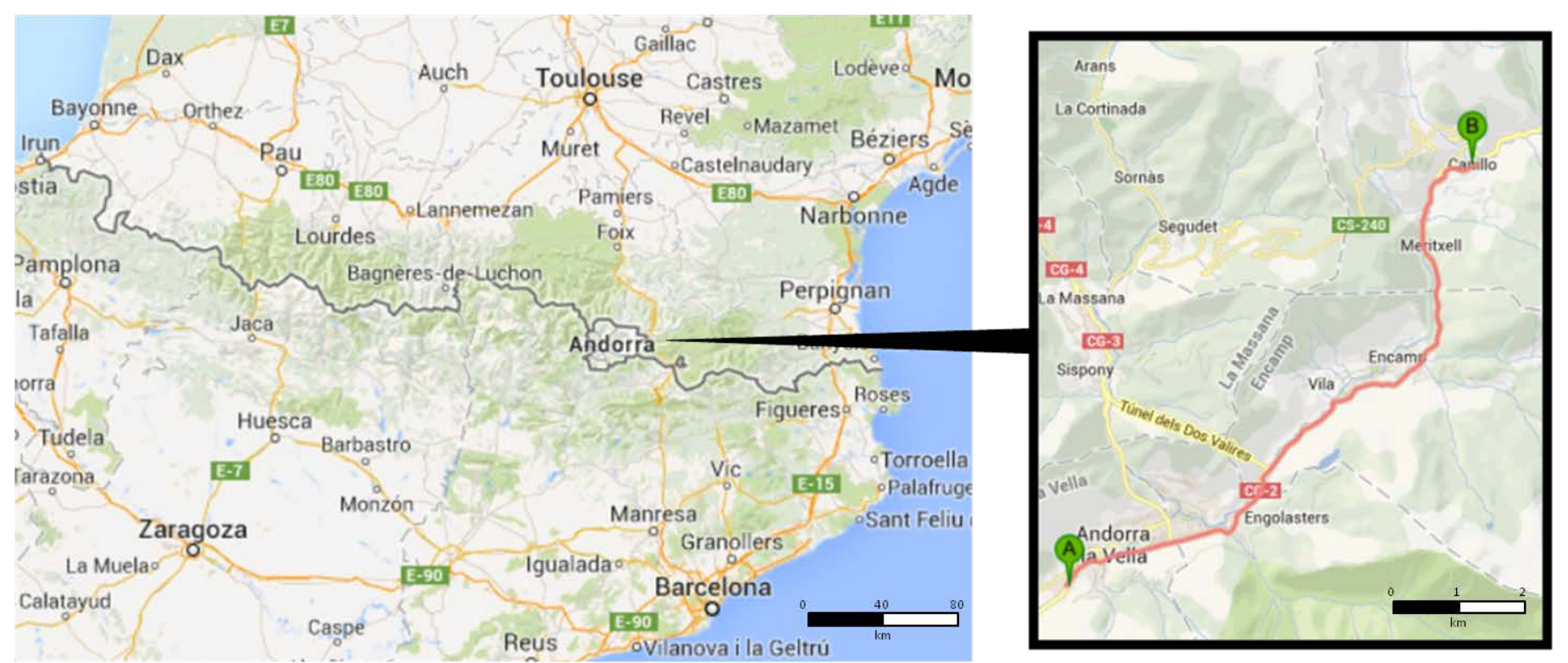

Fig. 1. Main route between Andorra la Vella and Canillo. (Source: Google Maps and Geocontext-Profiler)

In order to represent a detailed model of the route, a geographical information system has been used with specific road data. The elevation profile has been obtained using the topographic map of Andorra from 2003 (Andorra Government, 2003). An onsite survey using GPS has been performed to determine the exact location of several traffic elements like traffic lights, roundabouts, pedestrian crossings and speed limits. The results of this compilation are displayed in Fig. 2. 


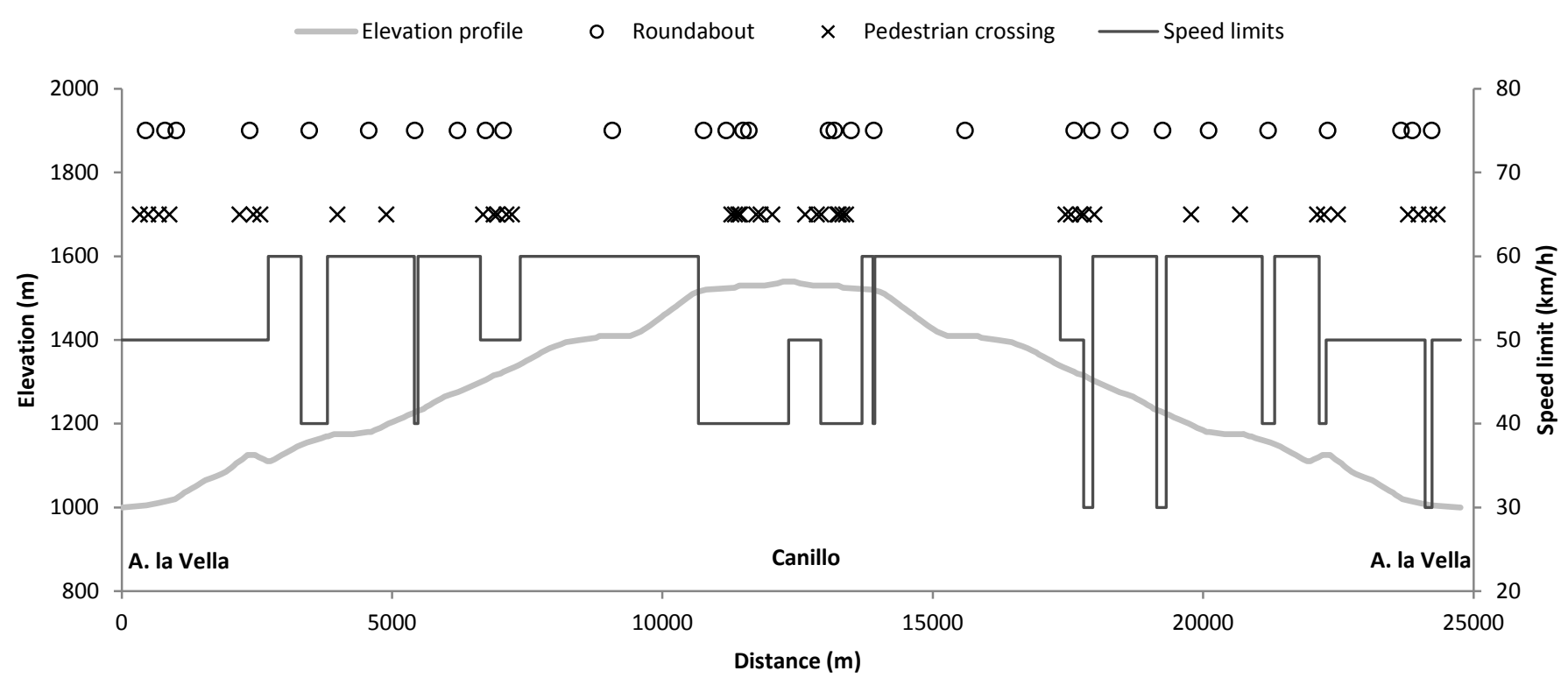

Fig. 2. Geographical data compilation of the round trip between Andorra la Vella and Canillo

As shown in Fig. 2, speed signals are less restrictive in the Andorra la Vella-Canillo stretch (mean speed limit of 53.59 $\mathrm{km} / \mathrm{h})$ than in the return trip $(46.04 \mathrm{~km} / \mathrm{h})$, coinciding with most uphill stretches. Speed limits are low, ranging from 30 to $60 \mathrm{~km} / \mathrm{h}$. Although the route has some extra-urban driving between Escaldes-Engordany-Encamp and EncampCanillo, the speed profile is more similar to an urban driving cycle. Traffic lights are considered as pedestrian crossings because all are controlled by pedestrian-crossing buttons.

\subsection{Model assumptions}

Two conventional diesel vehicles and their electric-equivalent models have been simulated in order to explore the effects of a hypothetical future electrification of the car fleet. Currently there are only a few vehicle models with both electric and ICE versions, although some of them are already available or will be available shortly. VW Golf has been selected because it represents a common European C-segment 5-seater vehicle and one of the dominant models both in the European market and for Andorra's vehicle fleet. Its electric version is called Golf Blue-e-motion (available in the UK from 2014). Toyota RAV4 represents J-segment sport utility cars (SUV), which is very common in mountainous regions and heavier than C-segment vehicles. RAV4 EV is one of the few all-electric off-road vehicles in the market, currently only available in California. For comparative purposes, vehicles with similar engine power have been selected.

Essential differences considered in the simulation between conventional and electric models are: (a) batteries, (b) engine, (c) regenerative braking, and (d) vehicle mass. In general, EVs are heavier than ICEVs due to the electric engine and batteries, although this is partially overcome by the decrease in weight due to the absence of a combustion engine and tank. Increases in vehicle mass have a determining impact on fuel consumption (Burgess and Choi, 2003; Tolouei and Titheridge, 2009), and this factor must be included in the model. According to the vehicle comparison presented in Thiel et al. (2010), EVs can be considered to be, on average, $185 \mathrm{~kg}$ heavier than diesel ICEVs. In the study, and following manufacturer's specifications, mass differential between EV and ICEV is $205 \mathrm{~kg}$ for Golf and $271 \mathrm{~kg}$ for RAV4. Relevant characteristics of the modelled vehicles are summarised in Table 1.

\begin{tabular}{|c|c|c|c|c|}
\hline & Golf diesel $^{\mathbf{1}}$ & Golf Blue-e-motion $^{\mathbf{2}}$ & RAV4 diesel $^{\mathbf{3}}$ & RAV4 EV $^{\mathbf{4}}$ \\
\hline Power (hp) & 105 & 115 & 150 & 154 \\
\hline Mass (kg) & 1295 & 1500 & 1558 & 1829 \\
\hline Drag coefficient (-) & 0.28 & 0.28 & 0.3 & 0.3 \\
\hline Frontal area (m) & 2.21 & 2.21 & 2.6 & 2.6 \\
\hline Battery capacity (kWh) & & 26.5 & & 35 \\
\hline
\end{tabular}

Table 1. Manufacturer's specifications of the simulated vehicles

\footnotetext{
${ }^{1}$ https://app-ssl.volkswagen.es/es/compra_un_vw0/catalogos.htx

${ }^{2}$ http://www.volkswagen.co.uk/about-us/futures/golf-blue

${ }^{3}$ http://www.toyota.com/espanol/rav4

${ }^{4}$ http://www.toyota.com/rav4ev
} 
Conventional vehicles are modelled considering an average engine and transmission efficiency. According to Bandivadekar et al. (2008), current ICEV transmission efficiency can be considered to be $89 \%$. Engine efficiencies of $28 \%$ for VW Golf and $24 \%$ for RAV4 have been taken, since they reproduce energy consumption results in the simulations (using the NEDC) consistent with those published by manufacturers.

Due to the absence of detailed information on batteries in the manufacturer's specifications for EVs, battery modelling has been based on current technology. EVs have been modelled with lithium-ion batteries with an energy density of $125 \mathrm{Wh} / \mathrm{kg}$ and a depth of discharge of $80 \%$ (Gerssen-gondelach and Faaij, 2012). Battery behaviour during charge and discharge has been considered to be lineal. As shown in Fig. 3, in our vehicle model, there are bidirectional energy flows between the vehicle socket and wheels through the AC/DC converter, battery, DC/AC converter, motor/generator and transmission.

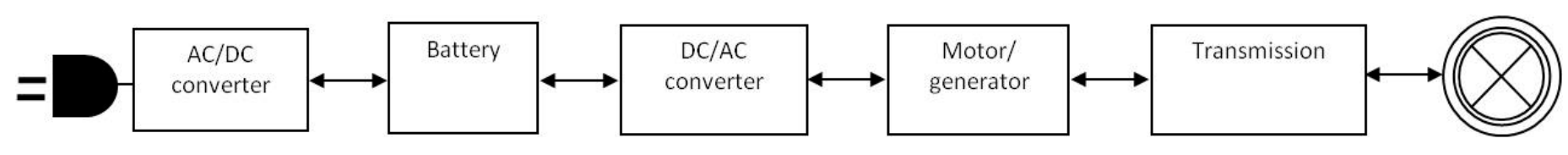

Fig. 3. Energy flow through the EV model

EV socket-to-wheels efficiency is taken as $69 \%$, based on the average values of EV components found in reviewed literature (Smith 2010a; Campanari et al. 2009; Hayes et al. 2011; Van Sterkenburg et al. 2011; van Vliet et al. 2011). A similar procedure has been followed to define the regenerative braking efficiency $\left(E_{R B}\right)$. $E_{R B}$ establishes which part of the energy otherwise wasted during deceleration and downhill motion is recovered with regenerative braking. Energy recovered flows through the wheels to the battery. Values range from 59\% to $84 \%$ (Van Sterkenburg et al. 2011; Smith 2010a; Campanari et al. 2009), resulting in a mean value of $69 \%$. Table 2 summarises these efficiencies for EV components including $E_{R B}$.

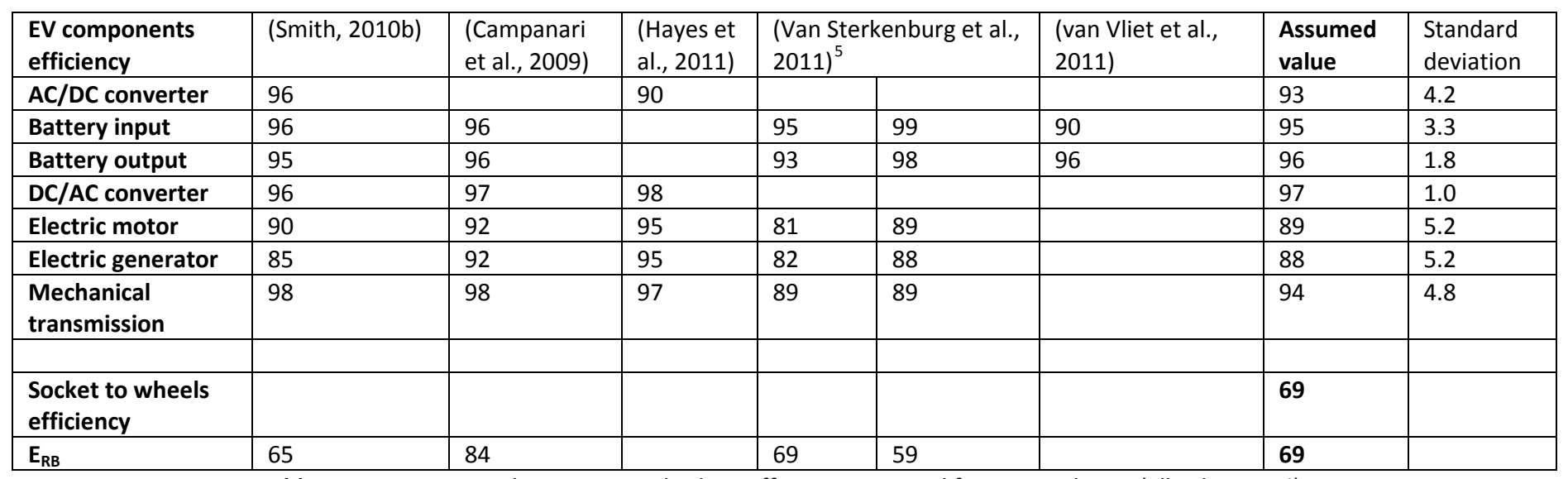

Table 2. Component and regenerative braking efficiency assumed for EV simulation (all values in \%)

Rolling resistance $\left(\mu_{r}\right)$ has a direct impact on fuel consumption. It depends essentially on tyre characteristics and road factors. The effect on total fuel consumption will vary according to a number of factors, including engine and drive train efficiency, as well as the amount of energy used by accessories. It is shown that a $10 \%$ reduction in the rolling-resistance coefficient can reduce total energy consumption by $2 \%$ (Burgess and Choi, 2003). For most passenger tyres sold in the United States, the tyre coefficient, measured when new, falls between 0.007 and 0.014 (National Research Council, 2006). According to JRC et al. (2013), and taking into account that the route is a paved road, a reasonable value of 0.007 is taken, both for ICEV and EV.

The model assumes that in real scenarios, the vehicle travels at a speed equal to the road's speed limits, except in the case of high traffic congestion. The vehicle stops 30 seconds at one out of every four pedestrian crossings. At roundabouts, it decelerates until it stops for 2 seconds and then it starts to accelerate again. The accelerationdeceleration rates are considered to be constant and vary depending on the driving style assumed in the different

\footnotetext{
${ }^{5}$ This paper describes the analysis of the efficiency of regenerative braking of two electric vehicles operating in the Rotterdam area.
} 
scenarios. The acceleration-deceleration values are based on De Vlieger et al. (2000), assuming $0.55 \mathrm{~m} / \mathrm{s}^{2}$ for calm driving, $0.725 \mathrm{~m} / \mathrm{s}^{2}$ for normal driving, and $0.975 \mathrm{~m} / \mathrm{s}^{2}$ for aggressive driving. These values are consistent with driving patterns representative of European driving presented in André et al. (2006). According to the authors, calm driving means anticipating other road users' movements, traffic lights, speed limits, and avoiding hard accelerations. Normal driving implies moderate acceleration and braking. By aggressive driving, sudden acceleration and heavy braking is meant.

In the next section, an energy consumption evaluation for EV and ICEV is presented. In order to obtain comparable results, a TTW analysis has been performed, providing relevant information on how efficiently the engine turns fuel into energy to impel the vehicle. Based on general legislative regulations (UNECE, 2013), as shown in Fig. 3, in the EV TTW analysis, energy flows between vehicle socket and the wheels, including charging losses.

\section{TTW analysis for ICEV and EV under different scenarios}

The energy consumption derived from TTW analysis is expressed in $\mathrm{Wh} / \mathrm{km}$. The TTW analysis expresses only final energy; a well-to-wheels (WTW) analysis would be necessary to determine primary energy consumption. The TTW ratio is defined in this paper as:

$$
T T W \text { ratio }=\frac{E_{T T W_{I C E V}}}{E_{T T W_{E V}}}
$$

This ratio expresses the improvement in TTW consumption for EV compared to ICEV. The EV range is also estimated for all scenarios in order to compare results for those obtained with the reference driving cycle used by manufacturers.

The characterised route can be travelled by vehicles in multiple scenarios, depending on factors such as traffic congestion and driving style. The main objective here is to quantify variability in consumption, in order to determine which factors affect vehicle performance most significantly. To do so, six scenarios have been assessed to analyse and compare the TTW behaviour of EVs and ICEVs. SO and S1 are unreal scenarios where speed is considered constant. These are used as null models for studying the effect of orography and traffic controls in detail. Table 3 gives a summary of the most important aspects of each scenario.

\begin{tabular}{|l|c|c|c|l|}
\hline Scenario & Orography & Road speed limit & $\begin{array}{c}\text { Traffic } \\
\text { controls }\end{array}$ & Driving style \\
\hline S0 & & & & Constant speed \\
\hline S1 & $\mathrm{X}$ & & & Constant speed \\
\hline S2.1 & $\mathrm{X}$ & $\mathrm{X}$ & $\mathrm{X}$ & Normal \\
\hline S2.2 & $\mathrm{X}$ & Half of maximum & $\mathrm{X}$ & Normal \\
\hline S3 & $\mathrm{X}$ & $\mathrm{X}$ & $\mathrm{X}$ & Calm \\
\hline S4 & $\mathrm{X}$ & $\mathrm{X}$ & $\mathrm{X}$ & Aggressive \\
\hline
\end{tabular}

Table 3. Summary of the scenarios considered

Table 4 shows TTW consumption and ratio for two conventional diesel vehicles and their electric-equivalent models and for all scenarios. The NEDC and Artemis urban (André, 2004) driving cycles have also been included as scenarios in the simulation, in order to be used as a reference for energy consumption. As similar trends have been observed for both vehicles, the results have been expressed as average values between two simulated EVs and ICEVs in Fig. 4 As can be seen, the results obtained for RAV4 (both versions) are higher than those for Golf, due to increased mass and poorer aerodynamic characteristics. In the off-road vehicle case, the TTW ratios are higher in all scenarios. These results are discussed thoroughly in the following subsections.

\begin{tabular}{|l|c|c|c|c|c|c|c|c|}
\hline & S0 & S1 & S2.1 & S2.2 & S3 & S4 & NEDC & Artemis urban \\
\hline Golf Diesel (Wh/km) & 193.89 & 437.43 & 544.40 & 429.43 & 507.99 & 582.10 & 387.09 & 556.94 \\
\hline Golf Blue-e-motion (Wh/km) & 75.91 & 145.98 & 174.45 & 136.51 & 163.71 & 185.47 & 136.02 & 174.72 \\
\hline Golf TTW ratio (-) & $\mathbf{2 . 5 5}$ & $\mathbf{3 . 0 0}$ & $\mathbf{3 . 1 2}$ & $\mathbf{3 . 1 5}$ & $\mathbf{3 . 1 0}$ & $\mathbf{3 . 1 4}$ & $\mathbf{2 . 8 5}$ & $\mathbf{3 . 1 9}$ \\
\hline & & & & & & & & \\
\hline RAV4 Diesel (Wh/km) & 284.20 & 630.43 & 782.64 & 615.93 & 730.35 & 836.85 & 563.64 & 799.49 \\
\hline RAV4 EV (Wh/km) & 93.98 & 179.04 & 213.52 & 166.69 & 200.39 & 227.01 & 167.97 & 213.52 \\
\hline RAV4 TTW ratio (-) & $\mathbf{3 . 0 2}$ & $\mathbf{3 . 5 2}$ & $\mathbf{3 . 6 7}$ & $\mathbf{3 . 6 9}$ & $\mathbf{3 . 6 4}$ & $\mathbf{3 . 6 9}$ & $\mathbf{3 . 3 6}$ & $\mathbf{3 . 7 4}$ \\
\hline
\end{tabular}




\begin{tabular}{|l|l|l|l|l|l|l|l|l|}
\hline & & & & & & & \\
\hline Time (min) & 27.44 & 27.44 & 47.13 & 69.03 & 50.90 & 43.95 & & \\
\hline
\end{tabular}

Table 4. TTW consumption and TTW ratio of simulated vehicles

\subsection{0}

So represents an ideal round trip between Andorra la Vella and Canillo, with a flat profile and no traffic controls. Constant speed $(53.95 \mathrm{~km} / \mathrm{h})$ is taken as the average of the speed limits along the route. It represents an unreal null scenario, built for comparative purposes. As shown in Fig. 4, S0 scenario has the lowest energy demand. This indicates, as expected, that a flat profile and constant speed minimise energy consumption in both vehicle technologies. In this scenario, the TTW ratio has the lowest value.

\subsection{1}

In this case, the orography factor is included in order to study the consequences of road grade, since it has a significant impact on energy consumption. In this scenario, ICEV energy consumption increases by $123.4 \%$ compared to S0. However, as shown in Fig. 4, the TTW ratio increases between S0 and S1, illustrating that the orography factor has a minor negative impact on EVs. Therefore, it is demonstrated that the energy-recovering capacity of regenerative braking outweighs the negative impact imposed by increments in mass in EVs.

\subsection{2}

S2 represents a real scenario with orography, traffic controls and a normal driving style. Two sub-scenarios are considered in this level, depending on traffic congestion: low traffic congestion assumes that vehicles could accelerate until they reach the speed limit for the route, while the high traffic congestion scenario assumes that maximum speed achieved by vehicles will be half of the maximum speed limit.

2.1) In the low traffic congestion scenario, ICEV energy consumption increases by $24.3 \%$ compared with S1 where traffic controls are not considered. This increase can be explained by the inertial force incorporated in the acceleration-deceleration process. The TTW ratio also increases, showing that EV has better energy performance than ICEV in a context with speed variability. It is also associated with EV's capacity to capture energy during deceleration.

2.2) In the high traffic congestion scenario, the results show that the energy consumption for the trip decreases by $21.2 \%$. Although trip time increases, the energy required per kilometre decreases due to lower vehicle speed. It also confirms that reducing speed limits is an effective way to decrease energy consumption. The TTW ratio is the highest among all real scenarios analysed, confirming that EV performance is significantly improved above ICEV performance when operating at low speeds and high speed variability.

\section{$3.4 S 3$}

$\mathrm{S} 3$ is a real scenario with low traffic congestion and a calm driving style. ICEV energy consumption is $6.7 \%$ lower than in S2.1, where normal driving behaviour is considered, and the TTW ratio decreases moderately until 3.40. The results are consistent with those obtained by Smokers et al. (2006) when analysing eco driving (6-10\%).

\subsection{4}

S4 is a real scenario with low traffic congestion and an aggressive driving style. ICEV energy consumption is 6.9\% higher than in S2.1, where a normal driving behaviour is considered. In the same way, the results show that energy consumption increases $14.6 \%$ with an aggressive driving style compared to calm driving behaviour. Literature suggests that aggressive driving results in a sharp increase in fuel consumption compared to normal driving (12-40\% for an aggressive driver depending on road type and vehicle technology) (De Vlieger et al., 2000; Nuzzolo et al., 2013). The low speed profile of our route, and its consequently lower speed variability, could explain the moderate increase in energy consumption obtained in the study. A small rise in the TTW ratio is achieved due to an increase in the deceleration rate, thus improving the EV's capacity to recover energy. 


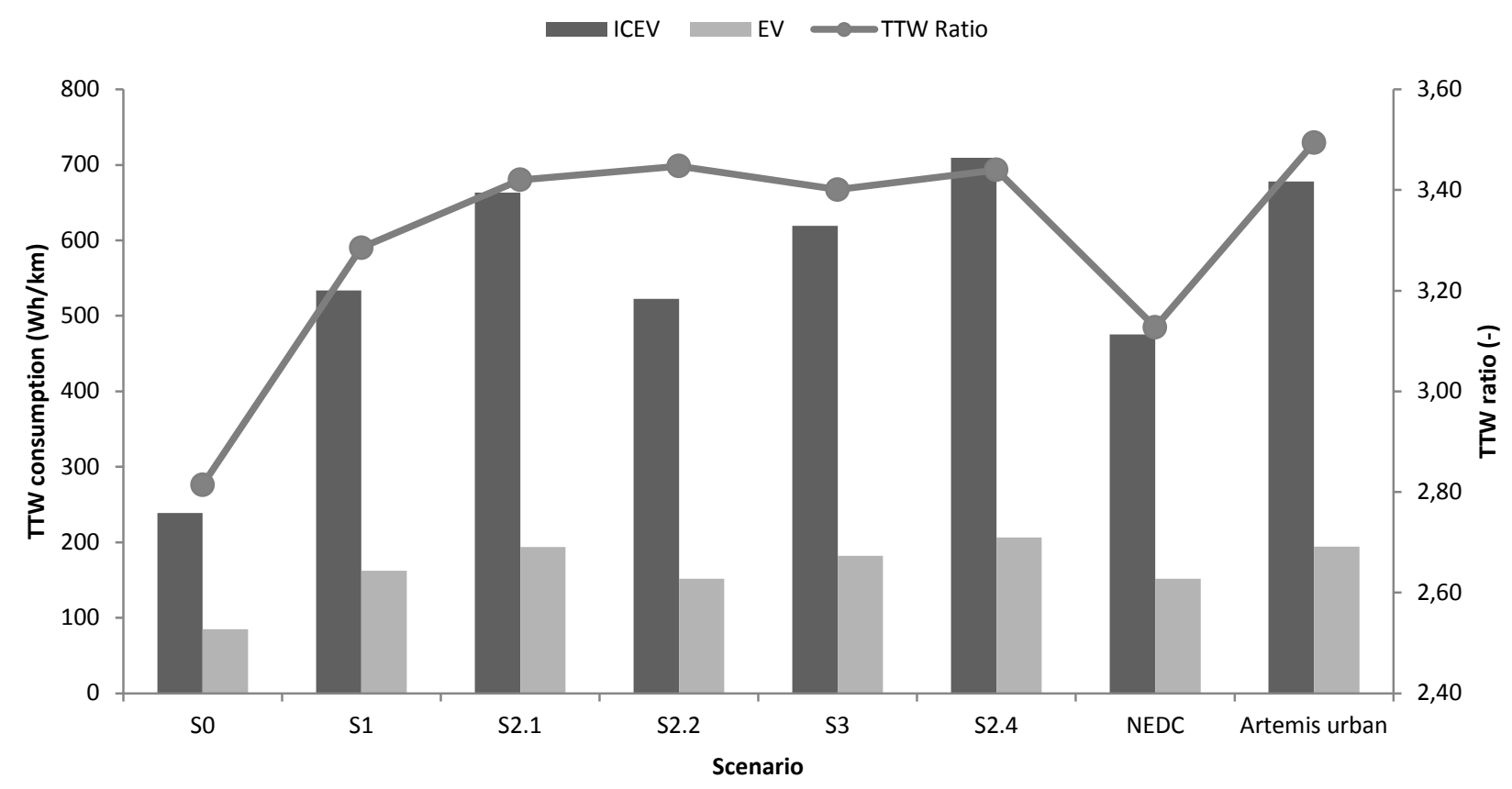

Fig. 4. TTW energy consumption and TTW ratio under different scenarios and driving cycles

\subsection{European driving cycles}

Some driving cycles used in measuring road fuel consumption have also been included in the comparative analysis. The NEDC has been selected because it is the European legislative driving cycle. It combines urban and extra-urban driving and is used for vehicle fuel economy and emission levels certification in the EU. It is considered by many authors to be a less aggressive cycle and non-representative of real world conditions. Comparing its results with those obtained in the scenarios above, it is shown that the energy consumption values obtained using NEDC are lower than those obtained by the modelled scenarios. In the case of EVs, the NEDC TTW energy consumption is $21.6 \%$ less than in $\mathrm{S2.1}$, the scenario where low traffic congestion and normal driving style is considered. For ICEVs, this value rises to $28.4 \%$. The TTW ratio is considerably lower than that obtained in the scenarios analysed, with the exception of the ideal trip, SO. This suggests, designed as it is, that the speed profile of the NEDC does not take full benefit of one of EV's salient features that is regenerative braking.

Artemis urban driving cycle has also been included as it represents urban driving conditions at lower speed and with more aggressive driving than in the NEDC. Based on these characteristics, energy behaviour might be expected to be more similar to the modelled road than in the NEDC. The Artemis urban driving cycle was developed within the European research project ARTEMIS (Assessment and Reliability of Transport Emission Models and Inventory Systems) and is based on the statistical analysis of a large database of European real-world driving patterns (André, 2004). The Artemis urban energy consumption results are very close to those obtained in S2.1 for both technologies analysed, $2.2 \%$ higher in the case of ICEVs and only $0.1 \%$ in EVs. The TTW ratio is slightly higher than those obtained in the different scenarios. This can be explained by the fact that the Artemis urban driving cycle has high speed variability, a factor that benefits EVs when compared to ICEVs.

\subsection{Orography, range and regenerative braking}

The results of our research support the fact that hilly routes increase vehicle energy consumption in both technologies analysed. Nonetheless, this type of orography affects consumption in differing degrees, depending on the vehicle technology. Although EVs are in general heavier than ICEVs, they fare better with changing road grades as energy is recovered on downhill sections. The same trends are observed for vehicle range, a factor that has a relative importance in ICEVs but that is significant in EVs. The limited range of EVs is considered one of the major barriers against massive adoption of electric cars (Shafiei et al., 2012; Sovacool and Hirsh, 2009). In our model, EV range is estimated and compared to those values obtained using the NEDC. Range results for EVs under analysis are shown in Table 5. In S2.1, the scenario where moderate acceleration and braking is considered, EV range is estimated to be reduced by $21.8 \%$ prior to the simulation using the NEDC. In the scenario where aggressive driving style is considered (S4), its value rises to $26.9 \%$. This fact could be considered as an extra limitation for EV market 
penetration in mountainous landscapes. These results may potentially be of interest for the long-term planning of charging stations in Andorra and other mountainous regions.

\begin{tabular}{|l|l|l|}
\hline Scenario & Golf Blue e-motion & RAV4 EV \\
\hline S2.1 & 122 & 131 \\
\hline S2.2 & 155 & 168 \\
\hline S3 & 129 & 140 \\
\hline S4 & 114 & 123 \\
\hline NEDC & 156 & 167 \\
\hline
\end{tabular}

Table 5. EV range $(\mathrm{km})$ of simulated vehicles

Other factors that were not considered in this research, such as electrical equipment, vehicle load, outside temperature and exposure to wind, can slightly affect EV range. Therefore in an extreme situation, range could be limited even more. Nevertheless, some studies point out that most daily vehicle mileage is significantly lower than EV ranges obtained in this and other results (Pearre et al., 2011).

As explained in Section 2.1, the characterised route is the round trip starting and ending in Andorra la Vella. The trip from Andorra la Vella to Canillo is generally uphill, with a mean road grade of $4.37 \%$. The return trip is downhill, a profile suited to regenerative braking. By analysing the evolution of energy consumed during the trip, a significant difference between ICEV and EV was detected. As shown in Fig. 5 (S2.1), energy consumption increases in ICEVs during the entire route and at a higher rate during uphill sections. In contrast, EV energy consumption stabilises its value on downhill sections. More specifically, at the middle point of the round trip (Canillo $-1540 \mathrm{~m}$ ), EV accumulated consumption is $4436.9 \mathrm{Wh}, 3.1 \%$ higher than at the final point (A. la Vella $-1005 \mathrm{~m}$ ). This is due to more energy being stored in the battery during descent than is consumed.

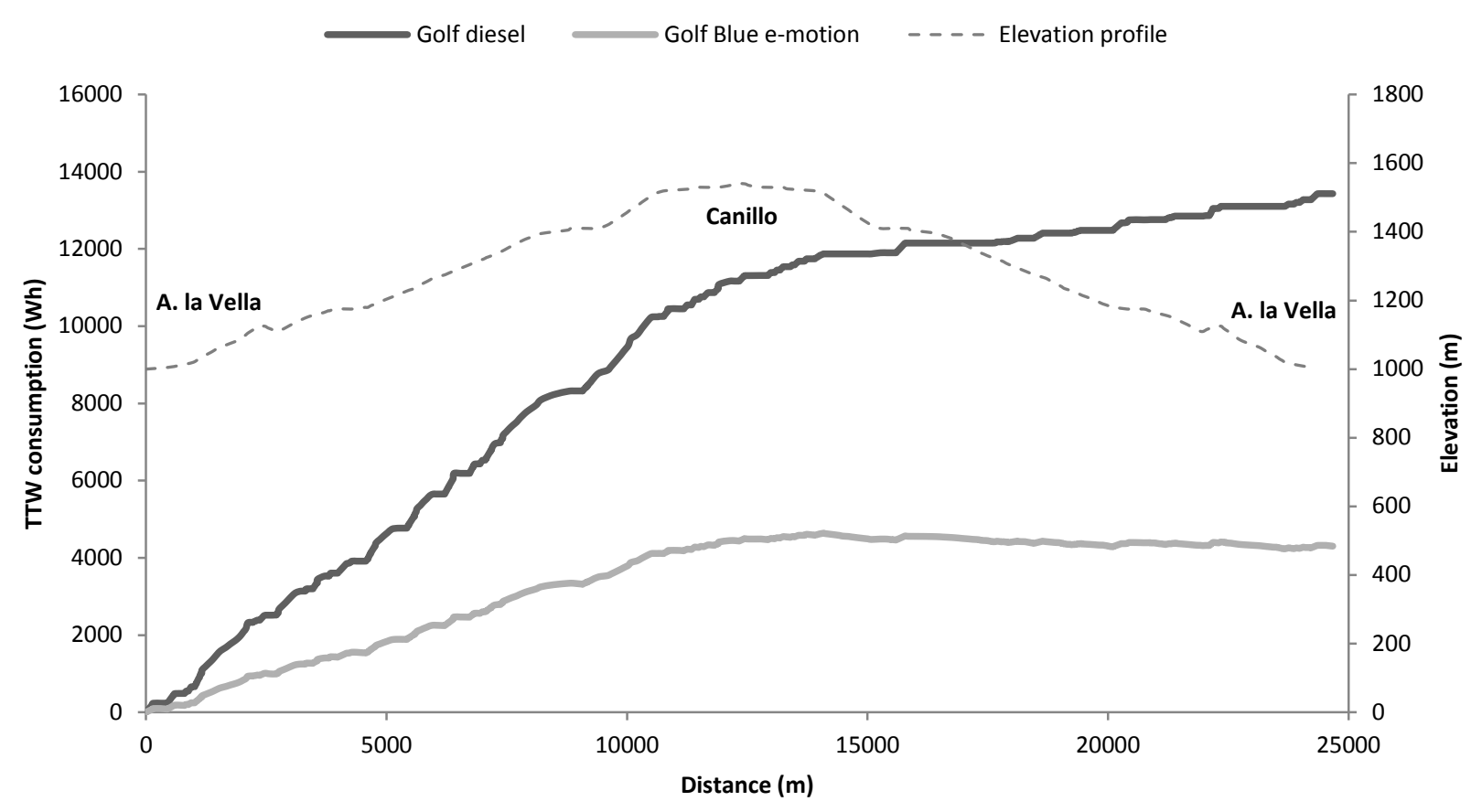

Fig. 5. Golf Diesel and Golf Blue e-motion TTW consumption in uphill-downhill route

This particular situation illustrates that if the round trip were started from Canillo with $100 \%$ battery level, less energy would be recovered because of the full battery. It would represent a loss in energy and lower improvement in TTW energy consumption for the EV compared to the ICEV. Fig. 6 shows the evolution of TTW energy consumption in this hypothetical trip for Golf EV. It can be observed that during downhill sections, EV energy consumption is very low, even $0 \mathrm{Wh}$ at some points. In that situation, there is a loss in energy because battery is at $100 \%$ and no more energy can be stored. Fig. 7 shows the battery state of charge (SOC), assuming an initial SOC of $100 \%$ and Canillo as the starting point of the route. EV accumulated energy consumption in the downhill-uphill route is $4506.5 \mathrm{Wh}, 4.5 \%$ higher than in the uphill-downhill route. Under these circumstances, there is a lower improvement in TTW consumption compared to ICEV. Golf TTW ratio is reduced from 3.12 to 3.08 . 

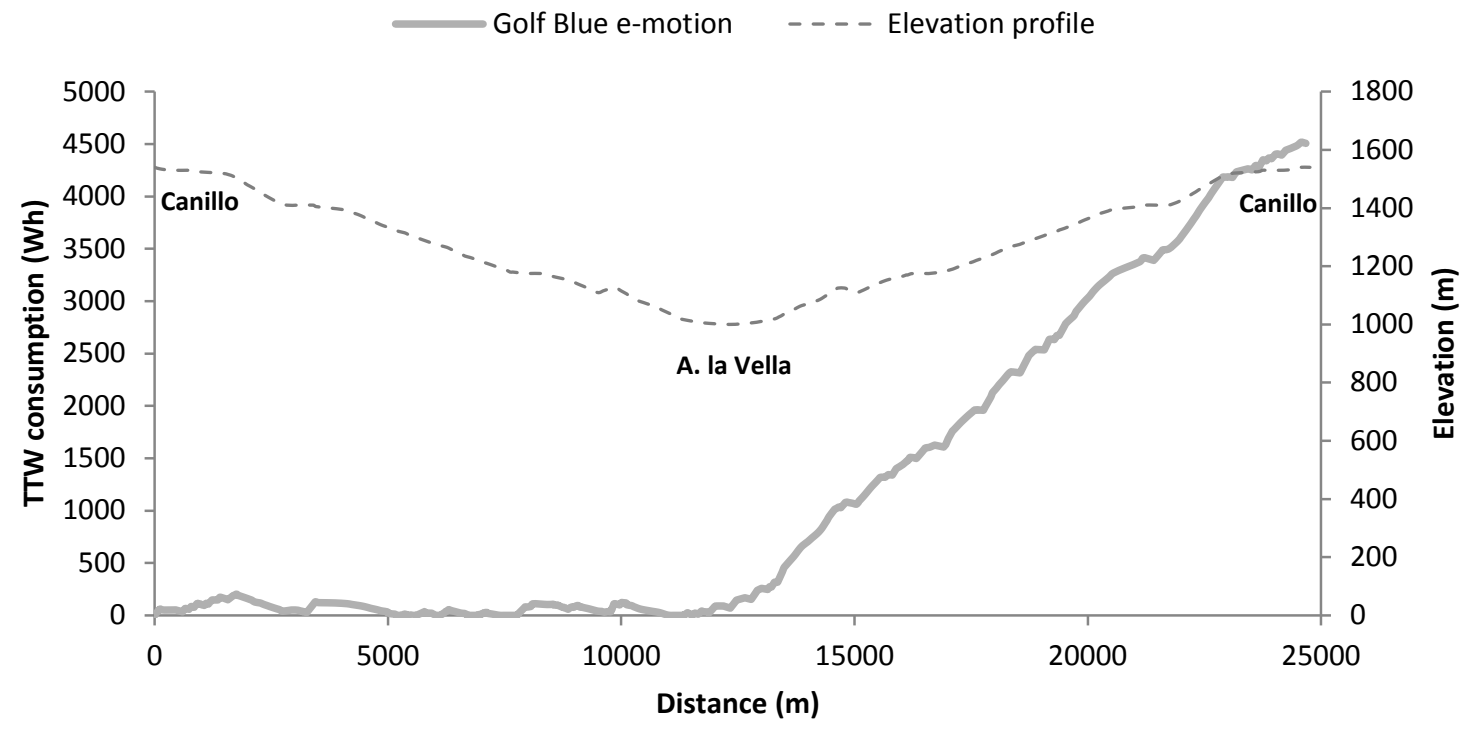

Fig. 6. Golf Diesel and Golf blue e-motion TTW consumption in downhill-uphill route

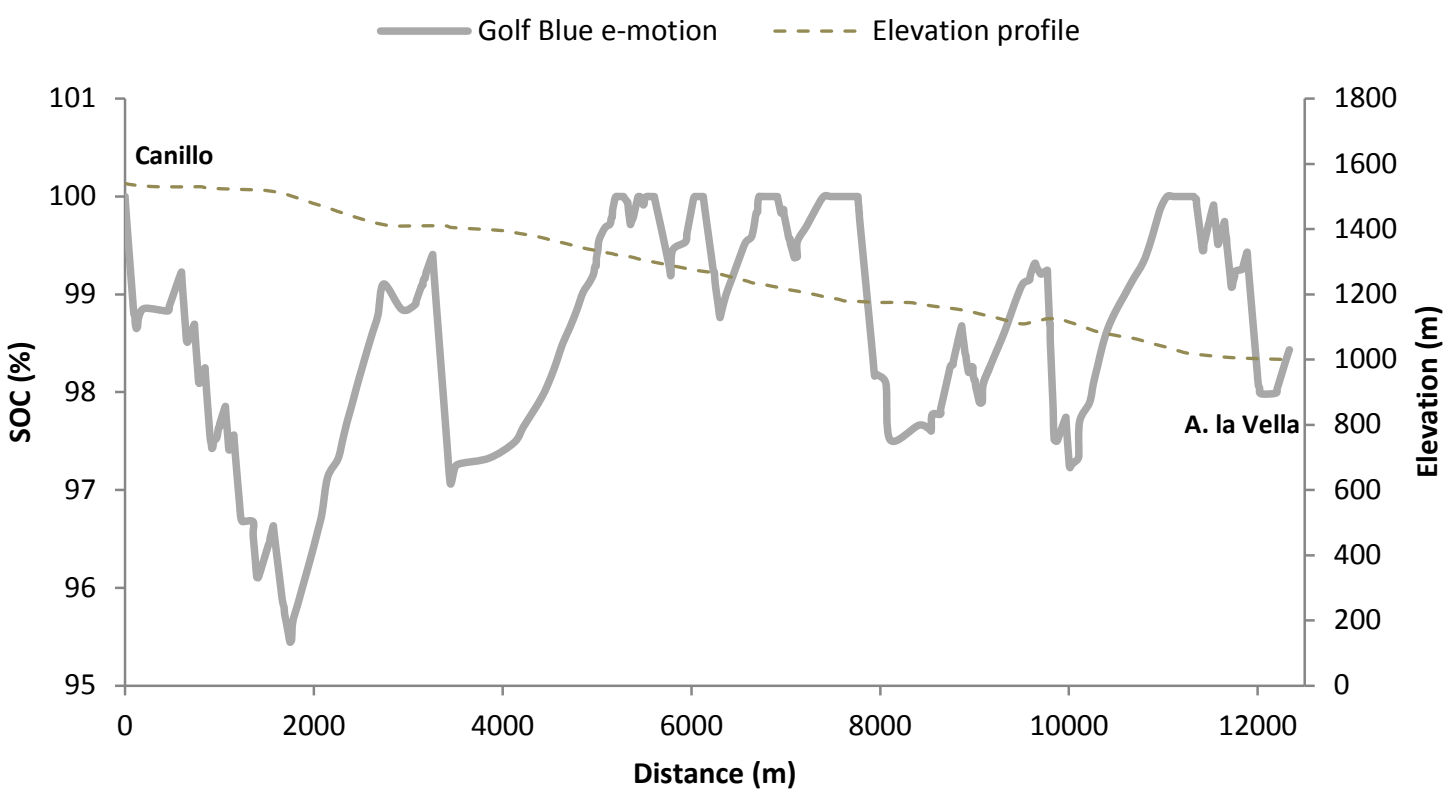

Fig. 7. Battery state of charge during downhill (Canillo-A. La Vella)

Together with the engine, regenerative braking is the key element in improving overall EV efficiency. In our simulations, and according to the literature, a value of $69 \%$ is taken for $E_{R B}$, resulting in a TTW ratio of 3.12, assuming S2.1 and VW Golf. Energy consumption and consequently TTW ratio is sensitive to this $E_{R B}$. In Fig. 8, a sensitivity analysis has been performed to determine how sensitive the model is to $E_{R B}$ changes. A simulation of the same scenario has also been included but taking into account a flat profile. As expected, with medium and high $E_{R B}$ values, the EV fares better with road grades than the ICEV due to the benefits of regenerative braking. As shown in Fig. 8, for $E_{R B}$ values lower than $20 \%$, the rugged terrain of the characterised route penalises the EV because the benefits of regenerative braking in this terrain are neutralised by greater energy demand resulting from its increase in mass. Nonetheless, all published data consider $\mathrm{E}_{\mathrm{RB}}$ to be significantly greater than $20 \%$. Thus, TTW ratios will always be higher in hilly regions than those for flat regions. 


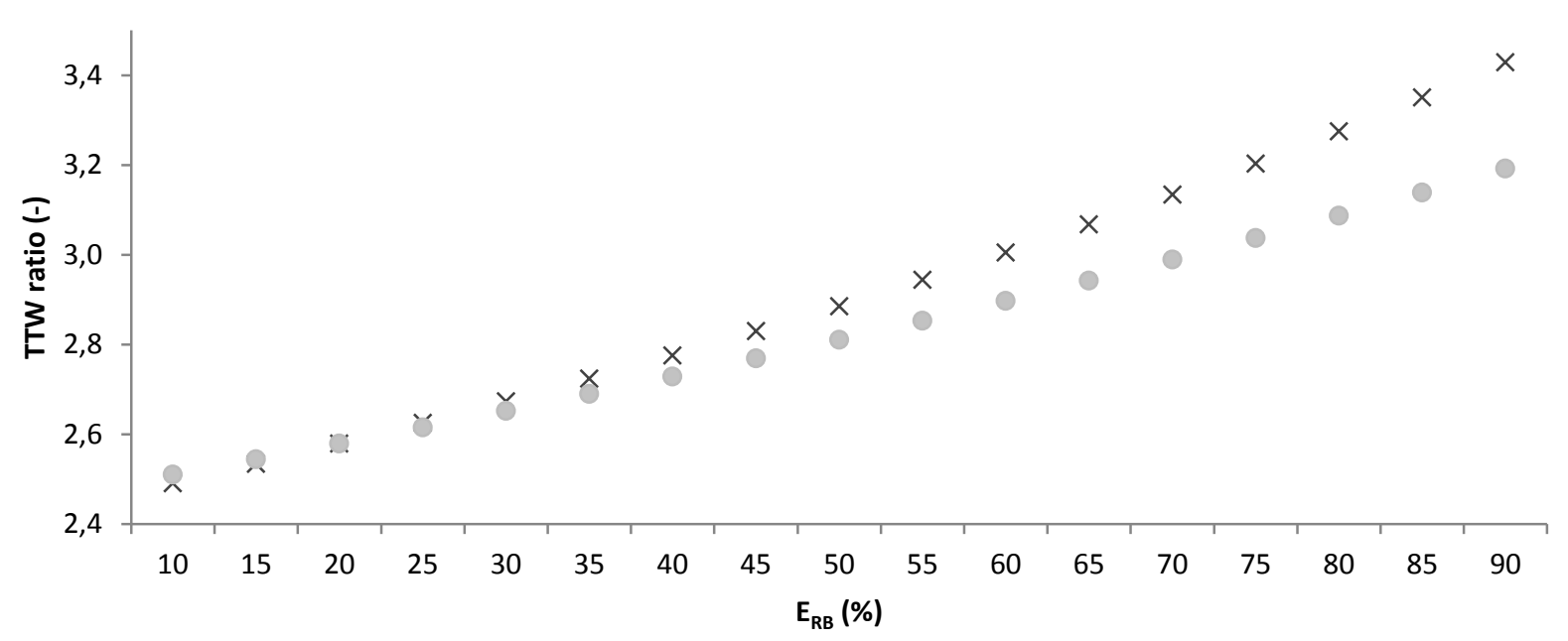

Fig. 8. Sensitivity analysis of $E_{R B}$ comparing hilly and flat profiles

\section{Conclusions}

In this paper, a real route from Andorra has been characterised in order to improve understanding about vehicle dynamics in mountainous roads. Two conventional diesel vehicles and their electric-equivalent counterparts have been simulated and their performances have been compared. The results show that road grades have a major impact on energy consumption, although they affect performance in differing levels, depending on the technology analysed. Although EVs are heavier than ICEVs, they are less affected by road grades as they can recover energy during deceleration and downhill. Savings in TTW consumption for the EV compared to the ICEV are more than three times higher in all real scenarios simulated, with a peak value of 3.45 obtained in the scenario where high traffic congestion is considered. Low speed limits and the mainly urban driving conditions of the characterised route mitigate the negative impact of road grades on energy consumption, ensuring that the introduction of EVs in Andorra would provide more energy savings than those estimated using the NEDC.

The results obtained in Andorra's reference route simulations show that the European legislative cycle NEDC, used to certificate car fuel economy and emission levels in the EU, is not representative for TTW energy consumption in hilly roads, and therefore is not useful to estimate overall consumptions in this landscapes. As a consequence, the EV range will be lower than that defined by manufacturers. Limited vehicle range is considered one of the major barriers against massive adoption of electric cars, and could represent an extra limitation for EV penetration in mountainous regions like Andorra. A reduction of $21.8 \%$ in EV range is estimated in the scenario where moderate acceleration and braking is considered. In a scenario where aggressive driving style is considered, this value could be as high as $26.9 \%$. In terms of TTW energy consumption, the results using the Artemis urban driving cycle are very similar to those obtained in the real scenarios from Andorra. According to data presented in this study, the use of the Artemis urban driving cycle is an alternative to take into consideration in future studies involving transport energy consumption in Andorra.

The $E_{R B}$ sensitivity analysis shows that, assuming medium and high $E_{R B}$ values, EV energy benefits are higher in hilly regions than in flat profiles. Only when unrealistic low $E_{R B}$ values are taken do rugged terrain penalise $E V$, because the benefits of regenerative braking in this terrain offset the greater energy demand due to the mass increase.

Under a scenario of widespread EV use in Andorra, some other relevant aspects such as well-to-wheels analysis and its importance with regard to greenhouse gases emissions, and its impact on power infrastructures and capacity, must be addressed in detail and will be explored elsewhere. 


\section{Acknowledgements}

The authors would like to thank Jose Luis Romeral and Josep Gili, from Universitat Politècnica de Catalunya Barcelona Tech, and Erik Schaltz, from Aalborg University, for their invaluable suggestions and comments. One author (OTB) acknowledges also a pre-doctoral grant from the Government of Andorra (ATC0012-AND-2013/2014).

\section{References}

Andorra Government, 2003. National topographic map. Scale: 1:5000. Contour lines with 25 m interval. Material from Ministeri d'Economia i Territori.

Andorra Government, 2012. Llibre Blanc de l'Energia d'Andorra.

André, M., 2004. The ARTEMIS European driving cycles for measuring car pollutant emissions. Sci. Total Environ. 334-335, 73-84. doi:10.1016/j.scitotenv.2004.04.070

André, M., Joumard, R., Vidon, R., Tassel, P., Perret, P., 2006. Real-world European driving cycles, for measuring pollutant emissions from high- and low-powered cars. Atmos. Environ. 40, 5944-5953. doi:10.1016/j.atmosenv.2005.12.057

Bandivadekar, A., Bodek, K., Cheah, L., Evans, C., Groode, T., Heywood, J., Kasseris, E., Kromer, M., Weiss, M., 2008. On the road in 2035: reducing transportation's petroleum consumption and GHG emissions.

Boriboonsomsin, K., Barth, M., 2009. Impacts of road grade on fuel consumption and carbon dioxide emissions evidenced by use of advanced navigation systems. Transp. Res. Rec. J. Transp. Res. Board. 2139, 21-30. doi:10.3141/2139-03

Burgess, S.C., Choi, J.M.J., 2003. A parametric study of the energy demands of car transportation: a case study of two competing commuter routes in the UK. Transp. Res. Part D Transp. Environ. 8, 21-36. doi:10.1016/S1361-9209(02)00016-0

Campanari, S., Manzolini, G., Garcia de la Iglesia, F., 2009. Energy analysis of electric vehicles using batteries or fuel cells through well-to-wheel driving cycle simulations. J. Power Sources 186, 464-477. doi:10.1016/j.jpowsour.2008.09.115

De Vlieger, I., De Keukeleere, D., Kretzschmar, J.G., 2000. Environmental effects of driving behaviour and congestion related to passenger cars. Atmos. Environ. 34, 4649-4655.

Department of Statistics, 2013. Andorra Government. URL http://www.estadistica.ad (accessed 10.28.13).

European Comission, 2013. Road transport: Reducing $\mathrm{CO}_{2}$ emissions from vehicles. URL http://ec.europa.eu/clima/policies/transport/vehicles/index_en.htm (accessed 10.28.13).

Frey, H.C., Zhang, K., Rouphail, N.M., 2008. Fuel use and emissions comparisons for alternative routes, time of day, road grade, and vehicles based on in-use measurements. Environ. Sci. Technol. 42, 2483-9.

Gerssen-gondelach, S.J., Faaij, A.P.C., 2012. Performance of batteries for electric vehicles on short and longer term. J. Power Sources 212, 111-129. doi:10.1016/j.jpowsour.2012.03.085

Hayes, J.G., de Oliveira, R.P.R., Vaughan, S., Egan, M.G., 2011. Simplified electric vehicle power train models and range estimation. 2011 IEEE Veh. Power Propuls. Conf. 1-5. doi:10.1109/VPPC.2011.6043163

IEA, 2009. Transport, Energy and $\mathrm{CO}_{2}$. Paris.

Jimenez-Palacios, 1999. Understanding and Quantifying Motor Vehicle Emissions and Vehicle Specific Power and TILDAS Remote Sensing. PhD dissertation. Massachusetts Institute of Technology, Cambridge.

JRC, CONCAWE, EUCAR, 2013. Tank-to-wheels report version 4.0. Well-to-wheels analysis of future automotive fuels and powertrains in the european context. Luxembourg. doi:10.2788/40409

Lorf, C., Martínez-Botas, R., Howey, D., 2013. Analysis of the energy consumption and $\mathrm{CO}_{2}$ emissions of 40 electric, plug-in hybrid electric, hybrid electric and internal combustion engine vehicles. Transp. Res. Part D Transp. Environ. 23, 12-19. doi:10.1016/j.trd.2013.03.004

Mari Svensson, A., Møller-Holst, S., Glöckner, R., Maurstad, O., 2007. Well-to-wheel study of passenger vehicles in the Norwegian energy system. Energy 32, 437-445. doi:10.1016/j.energy.2006.07.029

National Research Council, 2006. Tires and Passenger Vehicle Fuel Economy. Transp. Res. Board.

Nuzzolo, A., Musso, A., Crisalli, U., Rossi, R., Carrese, S., Gemma, A., La Spada, S., 2013. Impacts of driving behaviours, slope and vehicle load factor on bus fuel consumption and emissions: a real case study in the city of Rome. Procedia - Soc. Behav. Sci. 87, 211-221.

Park, S., Rakha, H.A., 2006. Energy and environmental impacts of roadway grades. Transp. Res. Rec. J. Transp. Res. Board. 1987, 148-169. doi: 10.3141/1987-16

Pearre, N.S., Kempton, W., Guensler, R.L., Elango, V. V., 2011. Electric vehicles: How much range is required for a day's driving? Transp. Res. Part C Emerg. Technol. 19, 1171-1184. doi:10.1016/j.trc.2010.12.010

Shafiei, E., Thorkelsson, H., Ásgeirsson, E.I., Davidsdottir, B., Raberto, M., Stefansson, H., 2012. An agent-based modeling approach to predict the evolution of market share of electric vehicles: A case study from Iceland. Technol. Forecast. Soc. Change 79, 1638-1653. doi:10.1016/j.techfore.2012.05.011

Smith, W.J., 2010a. Plug-in hybrid electric vehicles-A low-carbon solution for Ireland? Energy Policy 38, $1485-1499$. doi:10.1016/j.enpol.2009.11.031

Smith, W.J., 2010b. Can EV (electric vehicles) address Ireland's $\mathrm{CO}_{2}$ emissions from transport? Energy 35, 4514-4521. doi:10.1016/j.energy.2010.07.029 
Smokers, R., Vermeulen, R., Mieghem, R., Gense, R., Skinner, I., Fergusson, M., MacKay, E., Brink, P., Fontaras, G., Samaras, Z., 2006. Review and analysis of the reduction potential and costs of technological and other measures to reduce $\mathrm{CO}_{2}-$ emissions from passenger cars, Final Report, Report to the European Commission.

Sovacool, B.K., Hirsh, R.F., 2009. Beyond batteries: An examination of the benefits and barriers to plug-in hybrid electric vehicles (PHEVs) and a vehicle-to-grid (V2G) transition. Energy Policy 37, 1095-1103. doi:10.1016/j.enpol.2008.10.005

Thiel, C., Perujo, A., Mercier, A., 2010. Cost and $\mathrm{CO}_{2}$ aspects of future vehicle options in Europe under new energy policy scenarios. Energy Policy 38, 7142-7151. doi:10.1016/j.enpol.2010.07.034

Tolouei, R., Titheridge, H., 2009. Vehicle mass as a determinant of fuel consumption and secondary safety performance. Transp. Res. Part D Transp. Environ. 14, 385-399. doi:10.1016/j.trd.2009.01.005

Tzirakis, E., Pitsas, K., Zannikos, F., Stournas, S., 2006. Vehicle emissions and driving cycles: comparison of the Athens driving cycle (ADC) with ECE-15 and European driving cycle (EDC). Glob. NEST J. 8, 282-290.

UNECE, 2013. Addendum 100: Regulation No. 101.

Van Sterkenburg, S., Rietveld, E., Rieck, F., Veenhuizen, B., Bosma, H., 2011. Analysis of regenerative braking efficiency - A case study of two electric vehicles operating in the Rotterdam area. 2011 IEEE Veh. Power Propuls. Conf. 1-6. doi:10.1109/VPPC.2011.6043109

Van Vliet, O., van den Broek, M., Faaij, A., Brouwer, A.S., Kuramochi, T., 2011. Energy use, cost and $\mathrm{CO}_{2}$ emissions of electric cars. J. Power Sources. 8, 21-36. doi:10.1016/j.jpowsour.2010.09.119 